\title{
Evidence of low oxygen fugacity in the upper mantle domains beneath northeastern margin of Siberian \\ craton
}

\author{
V. ShATSKY ${ }^{1,2}$, A. RAGOZIN ${ }^{1,2}$, A. LOGVINOVA. ${ }^{1,2}$, R. \\ WIRTH ${ }^{3}$, V. REUTSKY ${ }^{1}$ \\ ${ }^{11}$ V.S.Sobolev Institute of Geology and Mineralogy, \\ Koptyuga ave., Novosibirsk, 630090, Russia. \\ shatsky@igm.nsc.ru \\ ${ }^{2}$ Novosibirsk State University, 2 Pirogova st., Novosibirsk, \\ 630090. Russia \\ ${ }^{3}$ Helmholtz Center, GFZ, 3.5 Surface Geochemistry, \\ Telegrafenberg, Potsdam, 14473 Germany
}

We demonstrate for the first time the wide presence of metalic melt inclusions in placer diamonds from the northeastern region of the Siberian craton. Metalic inclusions were identified in diamonds of both eclogitic and peridotitic paragenesis, which is demonstrated by olivine, sulfide, omphasite and $\mathrm{Kfs}$ inclusions. Most of the inclusions are heterogeneous in composition and consist of iron carbides, iron in various oxidation states, and carbon. In the diamonds we studied, metallic inclusions occur mainly in the outer part of the crystal grains. The presence of fragmented diamonds in the metallic inclusions suggests that the iron melt was carbon-rich. The diamonds containing metallic inclusions display large variability in $\mathrm{N}$ concentrations, ranging from below detection to $1640 \mathrm{ppm}$. Diamonds are characterized by a relatively low nitrogen aggregation state (5-35\%). The SIMS and FTIR spectroscopy data reveal no correlation between variations in carbon isotope ratio and nitrogen concentrations. Values $\delta^{13} \mathrm{C}$ in diamonds range from $-21,7$ to $-1,4 \%$. Diamond $\mathrm{Hi}-76$ has high nitrogen level (1400-1640) and lower aggregation state $(22-27 \% \mathrm{~B})$ and possesses a nearly uniform carbon isotope composition, with $\delta^{13} \mathrm{C}$ from $-21,7$ to $-21,1 \%$. The central part of diamond Hi-138 contains fractures filled with metallic phases. The $\mathrm{N}$ concentration in this diamond increases from 0 in central part to $520 \mathrm{ppm}$ in the rim. The core has slightly high $\delta^{13} \mathrm{C}$ value $(-1,4 \%)$ than rim $(-3,2 \%)$. Considering all these factors, the model for the interaction of the ascending asthenospheric mantle with the subducting slab seems to be more realistic. The interaction of the asthenospheric mantle and the subducting slab, which already contained diamonds, resulted in a temperature increase and reduction of iron oxides. 